\title{
Apuntes sobre las labores de protección de los diferentes derechos fundamentales a nivel mundial
}

\author{
Reflexiones a la luz de la jurisprudencia emitida por los diversos \\ Tribunales Internacionales de Derechos Humanos
}

Eloy Espinosa-Saldaña Barrera

1. Breves líneas acerca de la relevancia que ha adquirido el tratamiento de los derechos fundamentales en el constitucionalismo contemporáneo, y el importante rol que le corresponde a la jurisdicción internacional de los derechos humanos en dicho escenario

Pocos temas generan hoy tanto consenso dentro del constitucionalismo contemporáneo como el del reconocimiento de la relevancia adquirida por los Derechos Fundamentales dentro de los ordenamientos jurídicos de los diferentes países. Es más, a nivel doctrinario ya nadie discute que es imposible concebir un Estado social y democrático de derecho sin un verdadero respeto a la plena vigencia de dichos derechos ${ }^{1}$.

Por otro lado, son muy significativos los avances alcanzados en el proceso de internacionalización de los derechos fundamentales, fenómeno por el cual no solamente se ha conseguido la plena consagración y vigencia de los mismos en diversos estados (a pesar de las limitaciones existentes sobre el particular en los ordenamientos jurídicos de varios de ellos), sino también se han configurado instancias y procesos específicos destinados a asegurar la completa realización de tan importantes

1 Ver en este sentido lo expuesto entre otros por Elías Díaz-“Estado de Derecho y Sociedad Democrática». Madrid, Edicusa, 1975; Francisco Fernández-Segado- La Jurisdicción Constitucional en España. Madrid, Dykinson, 1984, p.13 y ss.; o Pablo Lucas Verdú-«Problemática actual de la justicia constitucional y del examen de constitucionalidad de las leyes". En: Boletín Informativo del Seminario de Derecho Político, Universidad de Salamanca, mayo-octubre. 1957, p. 99 y ss., por citar solamente algunos nombres. 
tareas tuitivas, conformando así lo que algunos ya consideran una verdadera jurisdicción internacional para la protección de estos derechos.

Sin embargo, en el desarrollo de las labores de defensa y promoción a las cuales venimos haciendo referencia, no solamente encontramos muchos avances como los aquí reseñados, sino también numerosas dificultades cuya relevancia no podemos soslayar. El objetivo del presente texto es pues precisamente, darnos una panorámica sobre el estado actual de la cuestión en este tan importante como delicado quehacer, a través de algunas experiencias específicas que en nuestra opinión son bastante representativas de las luces y sombras que el proceso de consolidación de la plena vigencia de los derechos debe hoy hacer frente. Pasemos pues a abordar de inmediato la tarea que nos hemos propuesto, para luego proceder a efectuar un comentario a modo de balance y síntesis de nuestra postura sobre el particular, compleja tarea en la cual -ojalá- nos desenvolvamos con suficiente fortuna.

2. Una positiva experiencia sobre el rol desempeñado por la jurisdicción internacional para la tutela de los derechos frente a las limitaciones existentes en algunos ordenamientos jurídicos nacionales para el desempeño de dichas labores: la aplicación de la teoría de los límites a los límites de los derechos fundamentales por el Tribunal Europeo de Derechos Humanos (TEDH)

2.1. Breve explicación de lo previsto por el TEDH sobre el particular y sus implicancias

Es oportuno aquí aclarar que el hoy prácticamente unánime reconocimiento de la gran relevancia reconocida a los derechos fundamentales no debe ser obstáculo para admitir, tal como ya lo han hecho reiteradamente algunos de los más calificados constitucionalistas de nuestro subcontinente $^{2}$, que el ejercicio de cualquier derecho fundamental no

2 En este sentido opina, por ejemplo, Germán Bidart Campos, cuando en una de sus obras más destacadas hace suya aquella antigua fórmula del derecho judicial argentino mediante la cual se enuncia la "relatividad de los derechos y garantías constitucionales». Ver entonces al respecto lo planteado en Germán Bidart Campos- La Corte Suprema. El Tribunal de Garantías Constitucionales. Buenos Aires, Ediar, $2^{\circ}$ ed., 1984, p.107. 
conoce de restricción alguna, sino que más bien está necesariamente sometido a algunos límites, los cuales pueden ser intrínsecos o extrín$\operatorname{secos}^{3} 45$.

Ahora bien, la lucha por la erradicación de la arbitrariedad en el quehacer de quien o quienes se desempeñan como autoridades, afortunadamente obligó a los juristas europeos a configurar algunas alternativas propias al respecto, con la particularidad de que en el viejo continente estas fórmulas no fueron planteadas por los jueces ordinarios o por los Tribunales constitucionales de los diferentes ordenamientos

3 Como bien sabemos, límites internos o intrínsecos son aquellos que se desprenden de la misma naturaleza jurídica o de la función social de cada derecho fundamental, y que sirven para definir el contenido mismo de dichos derechos. En cambio, los límites extrínsecos serían más bien aquellos originados por factores externos a cada derecho fundamental, pero que el ejercicio de esas importantes potestades bajo ningún concepto puede dejar de respetar. Estos límites extrínsecos incluirían pues tanto al contenido y ejercicio de otros derechos fundamentales como a la existencia de un conjunto de bienes jurídicos constitucionalmente protegidos. Acogemos entonces en líneas generales la clasificación empleada sobre el particular por Francisco FernándezSegado- El Sistema Constitucional Español. Madrid, Dykinson, 1992, p. 169 y ss.

$4 \mathrm{Y}$ es que como bien se señala en los importantes trabajos existentes sobre esta materia, la finalidad del juicio o examen de razonabilidad no es solamente el de evitar que mediante la regulación legislativa del ejercicio de diversos derechos fundamentales se proceda a destruir, degradar o extinguir dichos derechos, sino que su objetivo primordial es el de evitar que la actuación del detentador del poder devenga en abusiva o arbitraria. Ello en mérito a que, como bien señala Bidart Campos (Op. cit., p.108), lo razonable se opone a lo arbitrario, y siempre remite a una pauta de justicia.

5 Son muchos los trabajos que estudian los alcances de este juicio de razonabilidad en Argentina, evaluación que a su vez se sustenta en la defensa de la llamada dimensión sustantiva del Due Process of Law (o debido proceso legal), destacando nítidamente entre ellos el importante estudio de Juan Francisco Linares- Razonabilidad de las Leyes. Buenos Aires, Astrea, 1970.

En el estudio a su cargo Linares efectúa un minucioso estudio sobre la abundante jurisprudencia existente al respecto, jurisprudencia en la cual debemos incluir lo resuelto en Fallos 98-24, 253-154 o 300-700 (por solamente citar unos ejemplos), o las siempre interesantes $-\mathrm{y}$ hoy ya clásicas- sentencias emitidas en los casos Hileret y Rodríguez c/ Provincia de Tucumán (Fallos, 98-20) o "Cine Callao", también conocido como "el caso de los números vivos" (Fallos 247-121), sentencias de 1912 y 1960 respectivamente, aun cuando es por todos conocido que el primer antecedente que podemos hallar sobre este tipo de análisis se encuentra en el célebre proceso "Municipalidad de la Capital c. Isabel Viuda de Elortondo", proceso resuelto por la Corte Suprema Argentina en 1886 (ver sobre el particular Fallos 22-164). 
jurídicos nacionales, sino que han sido consecuencia de una reiterada jurisprudencia pacientemente apuntalada por organismos con pronunciamientos de alcance internacional tales como el Tribunal europeo de Derechos Humanos.

Nos encontramos aquí entonces, tan igual como podemos acreditarlo en otras materias, frente a un importante ejemplo sobre como vienen aportando las diferentes instancias de jurisdicción internacional en el fortalecimiento de las labores de tutela de los derechos fundamentales de diversos ordenamientos jurídicos estatales ${ }^{6} 7$, aspecto en el cual curiosamente no ha sido frecuente hacer mucha incidencia. Es más, habitualmente se suele soslayar como las múltiples construcciones jurisprudenciales elaboradas por estas instancias jurisdiccionales no solamente son útiles para consolidar el llamado proceso de internacionalización de los derechos fundamentales, sino que también tienen una

6 Bajo esta denominación de Jurisdicción Internacional estamos comprendiendo en principio a los tribunales previstos tanto en el sistema universal como en los sistemas regionales de defensa de Derechos Humanos, aun cuando ello no nos impide reconocer la importante labor que comienzan a desempeñar en este escenario algunas instancias supranacionales o comunitarias como el Tribunal de Justicia de las Comunidades Europeas (TJCE), instancia que actualmente ya cuenta con importantes pronunciamientos sobre el particular. Una completa explicación sobre las funciones del TJCE y sus aportes a la Tutela de los derechos fundamentales en el viejo Continente la encontramos en Paloma Biglino Campos- "¿iDe qué hablamos en Europa cuando hablamos de Derechos Fundamentales?", artículo publicado en la Revista de Estudios Políticos No 96, y luego reproducido en la Revista Jurídica del Perú No16. Trujillo, Normas Legales, julio-setiembre 1988, p. 27 y ss.

Por otro lado, y frente al posible cuestionamiento que pueda plantearse sobre los alcances de los conceptos "Derechos Humanos" y "Derechos Fundamentales", aclaramos desde ya que nosotros asumiremos ambos conceptos como sinónimos, con la única salvedad de que empleamos la acepción "Derechos Humanos" para aquellos derechos contemplados en las diferentes declaraciones y demás mecanismos de protección internacional previstos sobre el particular; en cambio, los alcances del término "Derechos Fundamentales" únicamente estarían reservados al ámbito de los diversos ordenamientos jurídicos nacionales.

7 Por cuestiones de tiempo y espacio aquí solamente nos limitaremos a esbozar en líneas generales los alcances de la Teoría de los límites a los límites de los derechos fundamentales. Entonces, para un completo desarrollo de los alcances de dicha teoría, recomendamos revisar nuestro artículo "La construcción jurisprudencial de la Teoría de los límites a los límites de los derechos fundamentales como mecanismo tuitivo de la vigencia de dichos derechos». En: Cáthedra. Lima, Universidad Nacional Mayor de San Marcos, 1999. 
vital importancia para ir superando los vacíos y deficiencias todavía existentes para el tratamiento de estos temas al interior de los Estados que libre y soberanamente se someten a la competencia de dichas instancias. Sin embargo, la innegable relevancia de esta materia obliga a explicar con un mayor detalle la experiencia vivida en Europa con la denominada «Teoría de los límites a los límites de los Derechos Fundamentales», postura elaborada por el Tribunal europeo de Derechos Humanos que recién hoy viene permitiendo a diferentes países de dicho continente alcanzar conclusiones similares a algunas de las habitualmente obtenidas en otros contextos mediante la aplicación del ya mencionado examen de razonabilidad, tarea que en mérito al interesante marco garantista que nos proporciona consideramos conveniente desarrollar a continuación.

Como es de público conocimiento, el Tribunal europeo de Derechos Humanos (de ahora en adelante TEDH) es la instancia con atribuciones de carácter jurisdiccional instituida para preservar el pleno cumplimiento de las prescripciones recogidas en el Convenio europeo de Derechos Humanos (CEDH). Este convenio (entendido por el TEDH como un parámetro o pauta mínima de obligatorio cumplimiento y tutela no solamente para todos los Estados signatarios del tratado internacional al cual venimos haciendo referencia, sino incluso también para los particulares residentes en dichos estados) le ha permitido al Tribunal de Estrasburgo ${ }^{8}$, dentro de las múltiples construcciones jurisprudenciales efectuadas por dicha instancia para neutralizar los arrestos arbitrarios de los gobernantes y apuntalar así mejor la defensa de diversos derechos fundamentales ${ }^{9}$, el no circunscribirse únicamente

8 Referencia vinculada con la ciudad en donde tiene su sede el Tribunal Europeo de Derechos Humanos, la ciudad de Estrasburgo (Francia). Ello también permite distinguirle de aquella otra importante instancia con atribuciones jurisdiccionales dentro del viejo Continente, el Tribunal de Justicia de las Comunidades Europeas (TJCE), con sede en Luxemburgo. Ahora bien, entre ambas instancias existen también otras importantes diferencias, siendo tal vez la más saltante el carácter comunitario de las labores del TJCE, tema que hemos abordado en otros trabajos.

$9 \mathrm{Y}$ es que la Teoría de los límites a los límites no es la única importante construcción jurisprudencial apuntalada por el Tribunal europeo de Derechos Humanos como parte de su estrategia tuitiva de la plena vigencia de diferentes derechos fundamentales. En esta misma línea va, por ejemplo, las evaluaciones destinadas a determinar cuando nos encontramos ante un trato discriminatorio (el llamado test de igualdad) 
a señalar (tal como lo hace en caos como el Ciulla) que los límites reconocidos al ejercicio de los diversos derechos recogidos en el CEDH deben ser interpretados restrictivamente, sino además el poder pasar a exigir que para dichas limitaciones resulten compatibles con el Convenio europeo de Derechos Humanos, las mismas que además deben responder a una serie de prescripciones ${ }^{10}$, las cuales en líneas generales pueden ser reconducidas dentro de estas tres aseveraciones:

a. Que los límites estén previstos en una ley anterior a su imposición al caso concreto que fuese de conocimiento del Tribunal europeo de Derechos Humanos: este criterio, invocado por el TEDH en reiteradas ocasiones, requiere sin embargo de importantes precisiones, máxime si en el escenario europeo la configuración del sistema de fuentes es muy distinta en función del ordenamiento jurídico de cada uno de los Estados suscriptores del Convenio europeo de Derechos Humanos.

Así por ejemplo, y desde el célebre caso Sunday Times (1979), el TEDH aclarará que su concepto de ley no se refiere exclusivamente

o frente a un proceso con un plazo razonable. Un buen acercamiento a estos aportes lo encontraremos en Teresa Freixes, "Las principales construcciones jurisprudenciales del TEDH». En: Cuadernos Constitucionales de la Cátedra Fadrique Furió No 10/ 11. Valencia, Universidad de Valencia, 1995, pp. 99-114.

$10 \mathrm{Y}$ es que si bien previsión legal, necesidad y proporcionalidad son en estricto las consideraciones exigidas por la construcción jurisprudencial del TEDH que aquí venimos analizando, un estudio más detallado de los diferentes pronunciamientos de dicho tribunal nos demuestra como también existen referencias a que los límites deben ceñirse a objetivos constitucionales (objetivos que, claro está, coinciden con aquellos que inspiran y/o están recogidos en el Convenio Europeo de Derechos Humanos); ser eficaces, idóneos o congruentes para obtener el fin propuesto; respetar el contenido esencial del derecho cuyo ejercicio ha sido limitado; constituir la alternativa menos gravosa o restrictiva para el normal desenvolvimiento del derecho fundamental en juego; y encontrarse debidamente motivados o fundamentados.

Asimismo, el TEDH ha sido reiterativo en insistir (criterio que por ejemplo también ha recogido el Tribunal Constitucional Español en su STC 26/1981) que la justificación de la limitación impuesta al ejercicio de un derecho fundamental (o dicho en términos más bien de corte procesal, la carga de la prueba de la validez de ese comportamiento restrictivo) corresponde a la autoridad que limita el ejercicio de dicho derecho, postura que, como luego veremos, es muy similar a la asumida por la judicatura argentina en la aplicación del denominado juicio de razonabilidad. 
a aquellas normas aprobadas a nivel parlamentario siguiendo un procedimiento supuestamente respetuoso del pluralismo que caracteriza a la composición de dicha institución, sino que asume como ley a toda disposición expresada con la suficiente claridad como para permitirle a cualquier ciudadano adaptar su conducta a lo allí dispuesto $^{11}$. Es por ello que, consecuentemente con dicha línea de pensamiento, este alto Tribunal considerará también como requisitos para definir si estamos o no ante una ley tanto a la necesaria publicidad oficial de las disposiciones sometidas a su análisis (en este sentido se pronuncia, entre otros procesos, en los casos Silver (1983), Malone (1984), etc.) como a la determinación sobre si existe en el ordenamiento jurídico del país adherente al convenio una reserva de la ley para la regulación de estos temas ${ }^{12}$. Fueron este tipo de requerimientos los que permitieron al TEDH concluir que en casos como el Silver ley no solamente es la ley penitenciaria inglesa, sino también el Reglamento de Prisiones vigente en aquel momento en dicho país, no pudiendo decirse lo mismo de una serie de instrucciones y circulares emitidas por las autoridades penitenciarias inglesas, en mérito a que éstas no habían sido publicadas oficialmente ${ }^{13}$.

Por otro lado, y además de esta comprensión más bien flexible del concepto de ley empleada por el TEDH (comprensión sustentada en consideraciones que bien podrían ser aplicadas a contextos completamente diferentes al europeo), es justo resaltar que frente al cada vez más polémico tema de la determinación de los márgenes de

11 Lo expuesto implicará también que cualquier ciudadano pueda ser capaz de, recabando los asesoramientos del caso, prever razonablemente las consecuencias que deberá producir un acto suyo contrario a la disposición a la cual el TEDH finalmente le reconocerá el carácter de Ley ya antes reseñado. Opina en este mismo sentido, Teresa Freixes-Op. cit. p. 103.

12 Es más, del mismo caso Malone se desprende que no solamente debe apreciarse si existen o no reservas de ley en función del tema en cuestión, sino también si el ordenamiento jurídico del estado signatario del TEDH acoge este tipo de previsiones.

13 Así es como el TEDH terminará también considerando como ley a aquellos reglamentos dictados por el gobierno francés al amparo de lo previsto sobre el particular en la Constitución de su Quinta República (1958), así como a todo reglamento autónomo, decreto legislativo o decreto de urgencia, normas en las cuales existe consenso en reconocerles fuerza o eficacia de ley. 
acción reconocidos como propios del legislador estatal ${ }^{14}$, también podemos apreciar como el Tribunal Europeo de Derechos Humanos ya ha establecido una clara posición al respecto, señalando que si bien se reconoce que el legislador estatal posee cierta discrecionalidad para imponer restricciones al ejercicio de determinados derechos, sus poderes no son ilimitados, y por ende, debe proporcionar garantías suficientes ya adecuadas para así por lo menos intentar evitar la comisión de abusos ${ }^{15}$.

b. Que los límites sean necesarios para conseguir un fin legítimo en una sociedad democrática: estamos aquí frente a un concepto cuyos alcances no son fáciles de precisar, en parte debido a que la formulación del mismo ha sido progresivamente evolucionando en la jurisprudencia que el TEDH ha emitido a lo largo de todos sus años de existencia. Y es que si bien originalmente el Tribunal europeo de Derechos Humanos señalaba que la referencia a lo necesario no debía entenderse como sinónimo de indispensable (postura asumida por el TEDH en el caso Handyside $(1976)^{16}$, luego pasará a afirmar que el término necesario implica la existencia de una exigencia social imperiosa (Caso Dudgeon (1981)), exigencia que obliga a la toma

$14 \mathrm{Y}$ es que el hoy indiscutido reconocimiento de la fuerza normativa de la Constitución no implica que ni la labor legisferante ni el producto de la misma, la ley, se hayan reducido a una mera aplicación mecánica de lo ya prescrito en el texto constitucional. Nada más lejano a la realidad que ello, pues la misma formulación más bien genérica de los diversos preceptos constitucionales da al legislador un amplio margen de acción sin que ello esté violentando lo previsto en la máxima norma del ordenamiento jurídico de cada país el legislador mantiene pues una gran discrecionalidad en su labor, aún cuando dentro de parámetros de carácter constitucional ya previamente establecido.

15 En este sentido, está por ejemplo lo resuelto en el caso Klass. Ahora bien, y tal como expresamente también lo señala dicho caso, no es necesario que las garantías a las que hacemos mención estén incluidas en la misma norma mediante la cual se ha procedido a limitar el ejercicio de alguno o algunos de los derechos recogidos en el Convenio Europeo de Derechos Humanos.

16 Cabe anotar además como en el caso "Handyside» el TEDH también incluye dentro de estos parámetros a la necesidad de proteger la moral, a pesar de reconocer la ausencia a nivel europeo de una noción uniforme de moral. Por ello resulta harto comprensible que esta referencia no haya sido en principio reiterada en los siguientes pronunciamientos del Tribunal Europeo de Derechos Humanos en los que se ha empleado la construcción jurisprudencial a la cual venimos haciendo referencia. 
de medidas que de todos modos, han de ser justificadas por la autoridad competente (Caso Gillow (1986)), con argumentos suficientes y pertinentes (Caso Sunday Times (1979)).

Por otro lado, el caso Young, James y Webster (1981) permitió al Tribunal europeo de Derechos Humanos anotar que los límites considerados como necesarios para sostener una sociedad democrática no deben entenderse como sinónimos de «útiles» u "oportunos", por lo cual ni la utilidad ni la oportunidad pueden ser esgrimidas como criterios para justificar la imposición de restricciones al ejercicio de diversos derechos fundamentales ${ }^{17}$; $y$ finalmente, en el caso Malone se consideraba que el cumplimiento del requisito de necesidad solamente puede darse si las medidas concretas tomadas recogían también suficientes garantías para evitar el uso abusivo de las mismas.

No quisiéramos concluir este apartado de nuestro relato sin precisar cuáles serían por lo menos algunos de los fines considerados como legítimos, y por ende, justificantes de una posible restricción al ejercicio de algunos derechos fundamentales. Aquí conviene por ejemplo hacer referencia a lo prescrito en el caso Klass (1978), en donde se señala como fines considerados legítimos (y por ello, susceptibles de recibir alguna clase de tutela) dentro de una sociedad democrática a la seguridad nacional, la defensa del orden y la prevención de las infracciones penales.

c. Que los límites sean proporcionales con relación al fin legítimo perseguido: Estamos aquí ante un tema ya esbozado en el caso "Sunday Times", pero desarrollado con un especial énfasis en «Young, James y Wesbster».

Resulta entonces importante resaltar cómo en el último proceso al cual hemos hecho mención, el TEDH no solamente exigió que las consideraciones esgrimidas para afectar la intimidad personal de los recurrentes debían ser especialmente relevante y adecuadas al fin perseguido, sino que también procedió a analizar si la restricción impuesta en este caso preciso era proporcional al fin social en el cual

17 Ahora bien, aquí también debemos efectuar algunas precisiones, pues ya desde el caso Handyside la necesidad invocada ante el Tribunal Europeo de Derechos Humanos exigía tener una especial relevancia, correspondiéndole a los Estados signatarios del CEDH el formular la valoración inicial de dicha necesidad (aporte del TEDH ya esbozado en el "Handyside», pero explicitado en el caso "Sunday Times"). 
reclamaba justificarse: el Tribunal para ello buscará tomar en cuenta los cambios que se hayan producido dentro de la opinión ciudadana en la percepción de los temas aquí abordados, elemento que considerará capital para apuntalar o recusar la pertinencia del límite invocado, sugerente postura que sin embargo ya ha causado no pocos cuestionamientos $^{18}$.

2.2. Análisis preliminar sobre las semejanzas y diferencias entre la Teoría de los límites a los límites de los Derechos Fundamentales y el juicio de razonabilidad, así como acerca de los efectos que puede generar la aplicación de esta construcción jurisprudencial en el caso europeo

Una exhaustiva revisión de los ordenamientos jurídico-constitucionales contemporáneos habitualmente vistos como los técnicamente mejor estructurados nos demuestra cómo el grueso de dichos ordenamientos nacionales hasta hoy no suelen contar con prescripción alguna sobre los alcances que pueden tener las diversas limitaciones susceptibles a imponerse al ejercicio de los diferentes derechos fundamentales. El riesgo de un comportamiento arbitrario y abusivo de quienes se desempeñan como detentadores del poder es pues insoslayable.

Justamente contra ese tipo de peligros es que aparecen construcciones jurisprudenciales como las de la Teoría de los límites a los límites de los Derechos Fundamentales y el examen o juicio de razonabilidad. Ahora bien, es evidente que a pesar de responder en abstracto a una misma finalidad, existen algunas diferencias en la configuración de ambas construcciones jurisprudenciales. Así por ejemplo, y si bien el TEDH

$18 \mathrm{Y}$ es que si bien aun cuando este tipo de interpretaciones es sin duda interesante y hasta cierto punto necesaria si nos encontramos ante una norma como el Convenio europeo de Derechos Humanos, la cual debe aplicarse a situaciones bastante heterogéneas entre si, coincidimos plenamente con quienes consideran que asumir posturas como la aquí reseñada presentan el gran inconveniente de introducir elementos de inseguridad jurídica que finalmente quiebren la pauta o parámetro mínimo de efectividad de los derechos que precisamente busca alcanzarse con la aplicación del Convenio europeo de Derechos Humanos. En este mismo sentido opina, por ejemplo, Teresa Freixes-Op. cit. p.104. 
reconoce que determinadas autoridades de cualquier estado tienen la capacidad de regular diversas situaciones con cierta amplitud de criterio, labor que pueden desempeñar a través de un mecanismo al cual habitualmente se le denomina como "Ley» (aún cuando éste no sea en rigor una ley formal ${ }^{19}$ ), sin duda alguna el margen de acción que proporciona el examen de razonabilidad al juzgador parece ser mucho mayor, ya que dicha evaluación, siguiendo las constataciones efectuadas por Germán Bidart Campos sobre el particular, no solamente se deduce de las leyes, sino que es extensiva a todos los actos estatales y de los particulares, como que en el amparo -por ejemplo- la arbitrariedad del acto lesivo es la herramienta clave para la procedencia del remedio, incluso también cuando la lesión proviene de actos de esos mismos particulares ${ }^{20} 21$.

19 Tal como ya hemos señalado en otro apartado del presente trabajo, el TEDH asume como ley a toda disposición en la cual se aborda cualquiera de los temas en los cuales el ordenamiento jurídico del país en cuestión ha admitido la existencia de una reserva legal, y además, a la que se reconoce el cumplimiento de determinados requisitos de publicidad oficial.

20 Ver al respecto Germán Bidart Campos-Op. cit. p.116.

21 Ahora bien, resulta interesante anotar como en principio la Corte Suprema Argentina señala que su interpretación de las leyes acusadas de restringir el ejercicio de algunos derechos fundamentales se efectúa en función a lo previsto en la ley, y no en términos de cómo se interpreta o aplica dicha norma (ver, entre otros, Fallos 294283). Sin embargo, nadie puede negar como en ocasiones la preocupación de dicha Corte se ha centrado en analizar como fue interpretada o aplicada una ley, o, dicho en otras palabras, cuales fueron las consecuencias y resultados obtenidos en su aplicación (en este sentido revisar Fallos 234-482 o el caso "Barros" (1979 Fallos 301 151). Es más, si estamos de acuerdo con lo señalado por Juan Francisco Linares sobre el particular (Op. cit., p.139), la Corte Argentina, en aquellos casos a los cuales considera como de clara irracionalidad técnico-social, ha procedido a pronunciarse sobre el manejo técnico o la conveniencia de las leyes. Corroborarían este planteamiento, entre otros ejemplos, lo resuelto en Fallos 132-402 (1920), 147-402 (1926), 150-89 (1927), 160-247 (1931) o 264-417 (1966).

$\mathrm{Y}$ es que, aun cuando existe algún precedente discordante (revisar al respecto Fallos 294-383), en líneas generales para la Corte Suprema Argentina «una ley puede ser atacada de inconstitucional no tan solo por lo que es en sí, sino por la interpretación con que ha sido aplicada por los tribunales locales y competentes». Es en este sentido que podemos encontrar numerosa jurisprudencia, jurisprudencia entre la cual destaca lo recogido en Fallos 186-353, o lo resuelto en el caso Cintioni Valdez C. (1979, Fallos 301-319). Lo expuesto entonces nos lleva al desarrollo de parámetros de inter- 
Por otro lado, y en lo referente a la búsqueda de un fin lícito o legítimo en una sociedad democrática, la postura asumida por el Tribunal europeo de Derechos Humanos se acerca mucho más a las exigencias reclamadas por la judicatura norteamericana que a lo tradicionalmente requerido por los juzgadores argentinos; pues a diferencia de lo que habitualmente ocurre en Argentina, en donde salvo en lo resuelto en algunos casos más bien recientes como el Reppetto, normalmente para considerar una decisión como razonable bastará con acreditar que existe una proporción adecuada entre el medio escogido y el fin buscado, la declaración de razonabilidad o irrazonabilidad en los Estados Unidos de América implicará junto a la no existencia de otra alternativa menos gravosa o restrictiva de los derechos fundamentales, el cumplimiento de un fin considerado como lícito dentro del ordenamiento jurídico norteamericano ${ }^{22}$.

Lo recientemente expuesto no quiere decir que la máxima instancia jurisdiccional argentina se haya desentendido de señalar cuando consi-

pretación similares a los empleados por el Tribunal europeo de Derechos Humanos, quien al confrontar lo previsto en los ordenamientos jurídicos de los países signatarios del CEDH no se circunscribe a aplicar lo explícitamente previsto en las leyes sometidas a su análisis, sino que hace su propia interpretación sobre el contenido y alcances de las mismas, interpretación que toma siempre en cuenta la opinión social dominante (en otras palabras, la forma como se entienden, aplican y asumen dichas leyes) existente al respecto. Ahora bien, es indispensable también reconocer que en el caso europeo estas interpretaciones deben estar cuidadosamente efectuadas y justificadas para que pueda admitirse su compatibilidad con lo previsto por el Convenio europeo de Derechos Humanos.

22 La mayor exigencia del cumplimiento de determinadas pautas para una declaración de razonabilidad o irrazonabilidad en el caso norteamericano ha tenido en nuestra opinión estrecha vinculación con el tema de determinar a quien dentro de un proceso le corresponde probar la irrazonabilidad de la decisión que viene cuestionándose. Así pues, mientras que en Argentina prima una presunción de constitucionalidad de la ley, y por ende, la irrazonabilidad debe ser probada por quien la alega (ver al respecto Fallos 247-121), en los Estados Unidos, y luego de una larga evolución de la jurisprudencia norteamericana sobre el particular, es por lo menos desde "Bakke» (1978), obligación de la autoridad cuya decisión restringe el ejercicio de algún derecho el acreditar que su actuación es necesaria para alcanzar el fin que venía persiguiendo. Un interesante estudio sobre el tratamiento dado a estos temas en los Estados Unidos de Norte América es indudablemente el efectuado por Miguel Angel Ekmekdjian y Pedro Siegler-Discriminación inversa: un fallo trascendente de la Corte Suprema de los Estados Unidos. En : El Derecho, t. 93, p.886. 
dera encontrarse frente a un fin lícito, y por ende, a una restricción razonable al ejercicio de algún derecho fundamental. Es más, y muy aparte de algún pronunciamiento más bien reciente más apegado a los patrones norteamericanos, eso es precisamente lo que hace en el célebre caso "Cine Callao", también conocido como el caso de los números vivos (Fallos, 247-121), en donde como bien sabemos la Corte asume como límites lícitos a la autonomía de la voluntad y la libertad de contratar de los dueños del cine antes mencionado a la creación de puestos de trabajo para artistas desocupados y a la preservación del patrimonio artístico de la sociedad. Sin embargo, justo es también anotar como en ese mismo proceso esa importante instancia jurisdiccional aclara que no le compete controlar la razonabilidad de los fines perseguidos por la ley, sino la razonabilidad del medio empleado para alcanzar esos fines, tema que abordaremos cuando analicemos el requisito de la proporcionalidad o adecuación del medio al fin buscado ${ }^{23}$. La postura asumida por el TEDH en este punto parece entonces ser bastante más radical, aunque, como bien podemos suponer, no han sido pocos los problemas que dicho tribunal ha debido afrontar para determinar cuando se encuentra ante un fin lícito y cuando la invocación a uno de estos fines es realmente pertinente.

Mención aparte merece el análisis efectuado desde ambas posturas jurisprudenciales sobre los medios (restrictivos del ejercicio de algunos derechos fundamentales) empleados para conseguir el fin pretendido. Como es por todos conocido, la Corte Suprema Argentina tradicionalmente se ha limitado a analizar si los medios (leyes) usados para alcanzar los fines buscados por la autoridad (legislador) son los adecuados o los proporcionales para cumplir con dicha tarea (en este sentido en-

23 Esta postura asumida por la Corte Suprema Argentina pareciera no haber sido acogida en lo resuelto en el caso "Canale C. Provincia de Mendoza" (1913, Fallos 118-278). En su sentencia sobre el particular la Corte dirá que en situaciones extraordinarias de manifiesto e insalvable conflicto entre medidas aparentemente tomadas para proteger la salud pública y lo prescrito en la Constitución Nacional le compete revisar no solamente si las mismas no tienen relaciones con sus fines aparentes, sino también si en ellas se ha desconocido derechos primordiales que el Poder Judicial debe amparar. Ahora bien, basta con efectuar un estudio algo más riguroso de lo resuelto en este proceso para comprobar como lo único realmente sometido a evaluación fue el medio empleado para intentar alcanzar los fines previstos, y no la licitud de los fines invocados. 
contramos casos como los recogidos en Fallos 247-121, 98-20, 171$348,199-485$, y un largo etcétera) ${ }^{24}$. El determinar si la autoridad debió elegir los medios dispuestos en una ley (o eventualmente mediante algún otro acto gubernamental, añadimos nosotros) u otros más eficaces y menos gravosos para la vigencia de los derechos fundamentales no sería entonces parte del análisis judicial de razonabilidad a tenor de lo planteado en múltiples pronunciamientos de la Corte, pronunciamientos entre los cuales conviene resaltar el recogido en Fallos 199-483.

Aquí sí fácilmente podemos pues apreciar como la postura asumida en este tema por el Tribunal europeo de Derechos Humanos guarda significativas coincidencias con lo previsto en el caso argentino, sobre todo a la luz de lo resuelto en procesos como los ya citados «Young, James y Webster" y "Dudgeon». Ahora bien, una reflexión sobre las diferencias a las cuales recientemente hemos hecho referencia nos permite apreciar como incluso esas diferencias, sin con ello querer soslayar su importancia, en esencia no nos llevan a conclusiones enfrentadas entre sí, ni a un tratamiento del tema abordado por ambas que sea sustancialmente distinto. Sin duda alguna, nos encontramos ante dos construcciones jurisprudenciales que con sus más y sus menos resultan muy similares, y pueden en el futuro proporcionarse mutuamente elementos que permitan a una enriquecerse con algunos de los logros conseguidos por la otra y viceversa.

Podemos entonces concluir este apartado de nuestro trabajo reconociendo que gracias a una construcción jurisprudencial como la de la Teoría de los límites a los límites de los Derechos Fundamentales ya existe en Europa (y sobre todo en Europa continental), muy a despecho de las restricciones existentes como consecuencia de la particular evolución de su constitucionalismo, una pauta para el razonamiento judicial que se encuentre en condiciones de generar efectos tan bene-

24 Ahora bien, el reconocimiento de que a la Corte solamente le interesa que el medio empleado guarde proporción o adecuación con el fin perseguido no impide que este Alto Tribunal, si lo considera pertinente, efectúe análisis, valoraciones y ponderaciones de las circunstancias que llevaron a tomar dichas medidas. Ello fue lo que ocurrió por ejemplo, en el célebre caso "Avico c. De La Pesa" (1934, Fallos 17221). Sin embargo, y como bien anota Bidart Campos (Op. cit. p. 115), lo expuesto bajo ningún concepto debe entenderse como un reconocimiento a la posibilidad de que los juzgadores puedan imponer sus criterios de conveniencia, eficacia económica o eficacia social, desconociendo así lo prescrito por el Congreso sobre el particular. 
ficiosos como los aportados por el examen o juicio de razonabilidad en los casos argentino o norteamericano. Sin embargo, nos queda aún por analizar un tema de indudable importancia: el de cómo asegurar la aplicación de estos criterios jurisprudenciales en un contexto tan heterogéneo como el que podemos encontrar en los diversos países signatarios del CEDH, máxime cuando algunos de ellos responden incluso a tradiciones jurídicas radicalmente diferentes. Es pues aquí donde la denominada Jurisdicción Internacional de los Derechos Humanos viene cumpliendo y está llamada a cumplir un rol trascendental en el fortalecimiento de la vigencia de los derechos fundamentales y el Estado de Derecho, tema sobre el cual siquiera efectuaremos algunos breves alcances.

\subsection{La labor del Tribunal europeo de Derechos Humanos (TEDH) destinada a asegurar la aplicación de la Teoría de los límites a los límites en los países signatarios del CEDH como ejemplo del importante rol que corresponde a la jurisdicción internacional en el fortalecimiento de la plena vigencia de los diferentes derechos fundamentales}

Nos encontramos entonces indudablemente ante un instrumento de indisimulable significación para preservar la plena vigencia de los Derechos Humanos o Derechos Fundamentales, según la denominación que queramos emplear al respecto ${ }^{25}$, máxime si del mismo texto del CEDH se desprende que de lo previsto en dicha norma o de la aplicación de la misma que hace el TEDH se configuran una serie de interpretaciones de aplicación general para todos los derechos, interpretaciones que a su vez resultan de obligatorio cumplimiento en los ordenamientos jurídicos de los Estados suscriptores del Convenio europeo de Derechos Humanos. Es importante además anotar, como dicha obligatoriedad no solamente es exigible a las Administraciones Públicas de aquellos Estados, sino también en la actuación cotidiana de los mismos particulares que residen en ellos. Ahora bien, justo es señalar que la forma en la cual se reconoce dicha obligatoriedad se ubica den-

25 Sobre la comprensión que le otorgamos aquí a los conceptos «Derechos Humanos" y "Derechos Fundamentales", recomendamos volver a remitirse a lo expuesto en la nota seis del presente trabajo. 
tro de los parámetros de estándar mínimo (prima lo dispuesto en el $\mathrm{CEDH}$ o por el TEDH solamente si asegura un mayor nivel tuitivo que lo ya previsto por el ordenamiento jurídico del Estado parte del Tratado Internacional al cual venimos haciendo referencia), lo cual parece tener la ventaja adicional de preservar la vigencia del escenario que apuntale una mejor defensa de los Derechos Fundamentales.

Estas últimas aseveraciones van a tener a su vez como importante consecuencia: la de asumir que el texto del CEDH y las diversas construcciones jurisprudenciales que hace el Tribunal de Estrasburgo en base a dicho Tratado Internacional (y entre ellas, la Teoría de los límites a los límites de los Derechos Fundamentales) se integran marcando importantes pautas dentro del ordenamiento jurídico de los diferentes países signatarios del $\mathrm{CEDH}$, países cuyos sistemas de derechos pasan a comprenderse asumiendo los parámetros interpretativos elaborados por el Tribunal europeo de Derechos Humanos. Curiosamente entonces, y a pesar de algunas significativas limitaciones aún subsistentes al respecto, la tradicionalmente restrictiva perspectiva del margen de acción otorgado en estos temas al juez europeo parece ir hoy más bien acercándose a una postura en la cual los derechos fundamentales, sus alcances e interpretación en el viejo continente únicamente es aquella que el Convenio europeo de Derechos Humanos o el Tribunal de Estrasburgo explícitamente admiten como válida ${ }^{26}$, muy a despecho de las previsiones constitucionales de cada estado firmante del $\mathrm{CEDH}$ en particular ${ }^{27}$.

26 Sin embargo, justo es reconocer que la validez de esta última aseveración cuyas reminiscencias a lo señalado por Oliver Wendell Holmes con respecto al caso norteamericano son a todas luces inocultables- no es tan concluyente como se quisiera, pues el proceso de integración y adecuación aquí descrito debe todavía hacer frente a importantes resistencias existentes al respecto. Pruebas de ello son por ejemplo algunos fallos del Tribunal Constitucional Federal Alemán sobre el particular, así como la discutida y discutible comprensión de los tratados como canon de constitucionalidad efectuada por el Tribunal Constitucional Español, temas cuyo análisis desafortunadamente rebasan los alcances del presente trabajo.

27 Ahora bien, y como ya adelantábamos siquiera someramente en otro apartado de este mismo texto, lo que hace aun más interesante esta incorporación de lo previsto por la Jurisdicción Internacional Europea al derecho interno de los países signatarios del CEDH es que lo resuelto en dicha instancia, en función del artículo 60 del tratado internacional antes mencionado (norma en la cual a saber se dice que "nin- 
La obligatoriedad que estaría otorgándosele a los preceptos y construcciones jurisprudenciales a los cuales hemos hecho referencia ha permitido entonces, entre otros logros, convertir a la Teoría de los límites a los límites en un eficaz instrumento para proporcionar alternativas mediante las cuales se asegura que el legislador y los demás aplicadores de las normas reguladoras del ejercicio de los derechos fundamentales respeten la plena vigencia de los mismos. Ello colateralmente además ha otorgado un importante elemento para incentivar no solamente el reconocimiento en toda Europa de la llamada dimensión objetiva de los Derechos Fundamentales ${ }^{28}$, incluso en aquellos estados cuyos textos constitucionales o los pronunciamientos de sus instancias de Jurisdicción Constitucional ${ }^{29}$ no la habían contemplado expresamente $^{30}$, sino también para apuntalar la necesidad de respetar la exis-

guna de las disposiciones del presente Convenio será interpretada en el sentido de limitar o perjudicar aquellos derechos humanos y libertades fundamentales que podrían ser reconocidos conforme a las leyes de cualquier Alta Parte Contratante o en cualquier otro convenio en que ésta es parte"), se incluye como un estándar o nivel mínimo. Lo que se quiere decir con ello es que si la regulación prevista en el país parte del CEDH es más tuitiva de los derechos fundamentales que lo previsto en el Convenio Europeo de Derechos Humanos o lo resuelto por el TEDH en particular, la aplicación de dicho tratado y estos criterios jurisprudenciales pueden ser en este asunto en específico ser dejados de lado. Lógica distinta es por ejemplo la invocable en lo referente a la normatividad comunitaria europea, la cual, al no plantearse como estándar mínimo puede desafortunadamente en algunos casos constituirse en nuestra modesta opinión en un riesgo de restricción al pleno ejercicio de determinados derechos en comparación a lo reconocido en ciertos ordenamientos jurídicos en particular.

28 Apelamos con esto a la moderna interpretación sobre los alcances de los derechos fundamentales que pone el énfasis en resaltar como su contenido y alcances van más allá de las siempre respetables pretensiones originarias de sus titulares, constituyendo hoy primordialmente un elemento básico para la configuración, comprensión y aplicación del ordenamiento jurídico de cualquier Estado Social y Democrático de Derecho que se precie de serlo.

29 Sobre la pertinencia de emplear los términos "Justicia" o "Jurisdicción" Constitucional, asumimos como más técnico y riguroso el acogernos a esta segunda acepción. En este mismo sentido recomendamos ver el esclarecedor análisis efectuado por Domingo García Belaunde-«Sobre la jurisdicción constitucional». En: Aníbal Quiroga León (Compilador) -Sobre la jurisdicción constitucional. Lima, Pontificia Universidad Católica del Perú, 1990, p.25 y ss., especialmente pp.29-31.

30 En este sentido apuntan los pronunciamientos del TEDH en los ya conocidos casos "Handyside" y "Plataforma Arzte für das Leben", procesos en los cuales el Alto 
tencia, regulación y demás alcances de todo lo referente a los derechos fundamentales en las diversas relaciones existentes entre particulares ${ }^{31}$. La importancia que en situaciones como las aquí descritas ha tenido la labor de una instancia de jurisdicción internacional como el TEDH es pues insoslayable, y además, constituye un interesante precedente que bien valdría la pena continuar.

Sin embargo, lo aquí expuesto no es obstáculo para reconocer como lamentablemente la consagración de escenarios tan auspiciosos como aquel al cual acabamos de hacer referencia es todavía susceptible de ser neutralizada o mediatizada si es que no se consiguen afirmar alternativas que permitan superar algunas evidentes limitaciones hoy existentes para asegurar la plena vigencia de lo resuelto por las diferentes instancias que actualmente componen la denominada Jurisdicción Internacional. Muy recientemente hemos visto en América Latina uno de estos casos, vinculado al abierto rechazo expresado por el gobierno del ingeniero Alberto Fujimori Fujimori a acatar el fallo emitido por la Corte Interamericana de Derechos Humanos en el caso «Castillo Petruzzi y otros", proceso en el cual se condenó al Estado peruano el 30 de mayo de 1999 por considerarse que se había violado diversos preceptos de la Convención americana de Derechos Humanos o Pacto de San José de Costa Rica. Sin ánimo de narrar aquí en detalle lo ocurrido en dicho caso, pasaremos pues a explicar muy sucintamente lo ocurrido al respecto para así tener una idea cabal sobre cuán difícil le resulta a una instancia encargada de tutelar internacionalmente los Derechos Fun-

Tribunal pondrá especial énfasis en resaltar la obligación estatal de garantizar la plena efectividad de derechos tan importantes como las libertades informativas y el derecho a manifestarse respectivamente.

$31 \mathrm{Al}$ respecto resulta sumamente ilustrativo lo resuelto en el caso «X e $\mathrm{Y}$ contra los Países Bajos», proceso en el cual el TEDH garantizó la obligatoriedad del Convenio europeo de Derechos Humanos y de sus propias construcciones jurisprudenciales no solamente para los Estados signatarios del CEDH, sino también en las relaciones con y entre particulares. Estupendos análisis sobre la pertinencia de esta aseveración en el escenario europeo, así como de las evidentes dificultades existentes para asegurar su completo cumplimiento son, entre otros, los efectuados por Juan María Bilbao Ubillos, La eficacia de los derechos fundamentales frente a particulares. Madrid, Cec-Boe, 1997; y anteriormente, el trabajo conjunto de Jesús García Torres y Antonio Jiménez Blanco-Derechos fundamentales y relaciones entre particulares. Madrid, Civitas, 1986. 
damentales el afrontar un problema tan delicado como el de preservar la plena ejecución de sus fallos, elemento central para asegurar que sus pronunciamientos surtan los efectos deseados por todos nosotros.

3. El problema de la ejecución de las sentencias como grave limitación al pleno desarrollo de la tutela de los derechos por instancias de carácter internacional a la luz de lo ocurrido en el caso "Castillo Petruzzi y otros contra el estado peruano»

3.1. Algunos alcances sobre el desarrollo del caso «Castillo Petruzzi», así como acerca del pronunciamiento de la Corte interamericana de Derechos Humanos al respecto

Como es de conocimiento general, toda la década de los ochenta y buena parte de la de los noventa el Perú vivió una gran convulsión social generada por el accionar terrorista de los grupos subversivos Sendero Luminoso (SL) y Movimiento Revolucionario Túpac Amaru (MRTA). Durante todo ese tiempo la estrategia antisubversiva asumida por los diferentes gobiernos peruanos siempre fue muy criticada por considerarse que era abiertamente violatoria de varios derechos fundamentales. Dicha percepción se hizo bastante más acentuada con la serie de decretos leyes dictados sobre el particular por el fujimorismo luego del autogolpe de abril de 1992.

$\mathrm{Y}$ es que luego de dictarse el Decreto Ley $\mathrm{N}^{\circ} 25475$, norma en la cual se tipifica a las manifestaciones subversivas más graves como parte del delito de terrorismo agravado. Ahora bien, muy pronto y gracias a los decretos leyes $\mathrm{N}^{\circ} 25659$ y $\mathrm{N}^{\circ} 25708$ estos casos de terrorismo, en los cuales ya se contaba con temas tan drásticos como la de la cadena perpetua, fueron asimilados a la figura de traición a la patria y sometidos a la competencia de jueces militares «sin rostro» ${ }^{32}$. En el segui-

32 Se habla de jueces "sin rostro" cuando nos encontramos frente a situaciones en las cuales la identidad del juzgador o los juzgadores es mantenida en el anonimato para así preservarles de presiones destinadas a condicionar el sentido de sus fallos. Este ha sido un sistema frecuentemente utilizado para proteger a quienes se han desempañado como jueces haciendo frente a casos de terrorismo o de delincuencia organizada, pero habitualmente ha sufrido múltiples cuestionamientos por considerarse que implica un 
miento de estos procesos se establecen una serie de importantes restricciones a las labores de los abogados de los acusados por subversión, restricciones que en nuestra opinión son abiertos e injustificados recortes al llamado derecho de defensa ${ }^{33}$.

A lo expuesto hay que añadir además lo dispuesto por el Decreto Ley $\mathrm{N}^{\circ} 25499$, o Ley de Arrepentimiento, y sus perniciosos efectos de comprometer a ciudadanos inocentes en las investigaciones, procesos y condenas por terrorismo ${ }^{34}$. Finalmente, a través de normas de similar naturaleza y características de las disposiciones antes mencionadas se procede a establecer una serie de condiciones para el desarrollo de los procesos y el encarcelamiento de los presuntos o comprobados subversivos realmente atentatorias de la libertad, dignidad y la integridad personal ${ }^{135}$. Es en este contexto en el cual, luego de una larga investi-

límite completamente desproporcionado al ejercicio de algunas de las garantías más importantes para conseguir la consagración de un debido proceso.

33 Algunas de esas restricciones son notorias en el caso «Castillo Petruzzi y otros», pues en dicho proceso, en estricta aplicación de la normatividad a la cual hacemos referencia, se proporcionó a los abogados de los condenados por terrorismo un acceso sumamente restringido al expediente que recogía dicho proceso (en ningún caso el plazo en cuestión fue por más de una hora, el cual le fue otorgado a los abogados de los presuntos subversivos chilenos solamente en una ocasión el día anterior a la lectura de la sentencia de primera instancia, muy a pesar que el expediente al que venimos haciendo referencia tenía una extensión de unos mil folios); y además, no se les permitió contar con asistencia legal desde la fecha de su detención hasta su declaración ante la división policial especializada en casos de terrorismo (DINCOTE), momento en el cual recién se les asignó un defensor de oficio.

Finalmente, los abogados de Castillo Petruzzi y los demás implicados en este proceso no pudieron interrogar a los testigos que fundamentaron la acusación ni a los policías y militares que participaron en las investigaciones seguidas en contra suya. Frente a todas estas situaciones, no nos queda más que coincidir con la Corte Interamericana de Derechos Humanos cuando asume que aquí estamos ante flagrantes violaciones de los artículos 8.2.b, 8.2.c, 8.2.d y 8.2.f del Pacto de San José, vinculados a la oportunidad y medios adecuados para preparar la defensa, al derecho a elegir abogados y a interrogar testigos respectivamente.

$34 \mathrm{Y}$ es que el contexto en el cual los «arrepentidos» obtenían el recorte e incluso la exención de sus penas, el de la delación de sus antiguos camaradas, llevó a que muchas veces se efectuasen denuncias falsas que determinaron la detención e incluso condena de cientos de personas inocentes, las cuales no tenían mayor vinculación con actividades subversivas.

35 De acuerdo con lo previsto por uno de los Decretos Leyes aprobados luego del 
gación policial, se produce la captura y detención del ciudadano chileno Jaime Castillo Petruzzi y de otras tres personas de la misma nacionalidad $^{36}$, todos ellos acusados de ser conspicuos miembros del Movimiento Revolucionario Túpac $\mathrm{Amaru}^{37}$, y por ende, sometidos a un juzgamiento ante el fuero militar peruano por traición a la patria.

En ningún momento se cuestiona si Castillo Petruzzi y sus compatriotas son inocentes del cargo que se les imputa (es más, los elementos que indicaban su participación en el MRTA fácilmente nos quitaban toda duda al respecto), sino que las pautas de procesamiento y reclusión aplicadas a estos casos han sido violatorias de varios derechos fundamentales. Es pues entonces que, luego de ser llevado este proceso a

autogolpe de 1992, el plazo máximo dentro del cual la Policía Nacional puede mantener la detenido por terrorismo sin ponerlo a disposición del juez competente puede ser prorrogada quince días adicionales a los quince ya previstos por la Constitución de 1979 para estos casos.

El plazo de treinta días sin posible participación judicial en esas labores de investigación se nos presenta entonces como una abierta y desproporcionada restricción a la libertad personal de quienes son detenidos en estas condiciones. Pero por si esto no fuese suficiente, en el caso "Castillo Petruzzi y otros" los cuatro detenidos por terrorismo permanecieron sin ser puestos a disposición de los jueces competentes por treinta y cinco a treinta y seis días, lo cual -aun admitiendo una eventual razonabilidad del plazo de detención de treinta días antes reseñado- implica una vulneración del derecho a la libertad personal a todas luces inaceptable.

Por otro lado, también en el contexto de los Decretos Leyes dados en 1992 se estableció para todos los detenidos por terrorismo agravado sean sometidos a un sistema de aislamiento celular continuo durante su primer año de reclusión. Ello vino complementado con prácticas como la de presentar a los detenidos a las diligencias de declaración ante las autoridades judiciales vendados, encapuchados, "amarrocados" o "engrilletados", lo cual a todas luces configura un conjunto de situaciones abiertamente violatorias de los artículos 5.1 y 5.2 de la Convención Americana de Derechos Humanos.

36 Jaime Castillo Petruzzi, sindicado hasta el momento de su detención como el número tres dentro de la estructura de mando del Movimiento Revolucionario Túpac Amaru, fue detenido el 15 de Octubre de 1993. Un día antes de dicho acontecimiento habían sido capturados sus compatriotas María Concepción Pincheira Sáez, Lautaro Enrique Mellado Saavedra y Alejandro Luis Astorga Valdez.

37 Los cuatro ciudadanos chilenos detenidos en Octubre de 1993 fucron los directos responsables de varios asesinatos y secuestros, así como de la conducción de las llamadas "cárceles del pueblo", lugares en donde los terroristas del MRTA retenían a importantes personalidades con el fin de obtener significativas cantidades de dinero a cambio de su liberación. 
la Corte por la Comisión Interamericana de Derechos Humanos, el Alto Tribunal que sesiona en San José de Costa Rica condena al Perú por considerar que aquí se han vulnerado los artículos $1.1,2^{\circ}, 5^{\circ}, 7.5$, 7.6, 8.1, 8.2.b, 8.2.c, 8.2.d, 8.2.f, 8.2.h, 8.5, $9^{\circ}$ y $25^{\circ}$ de la Convención americana de Derechos Humanos, disponiendo además que el Estado peruano efectúe un nuevo juzgamiento de los cuatro presuntos subversivos chilenos, esta vez sí respetuoso de todas las diversas garantías procesales propias de un debido proceso.

Por razones al parecer muy marcadas por la coyuntura pre-electoral que ya se vive en el Perú, el gobierno fujimorista y su entorno ${ }^{38}$, luego de un curioso intento de declarar inejecutable el fallo de la Corte Interamericana de Derechos Humanos emprendida por el Consejo Supremo de Justicia Militar ${ }^{39}$, ya no solamente se circunscribirán a

38 El Estado Peruano tiene el triste récord de ser el que ha recibido más condenas de la Corte Interamericana de estos últimos años, y además, el que posee más procesos abiertos ante la Comisión Interamericana de Derechos Humanos, procesos que en buena parte llegarían a ser de conocimiento de la Corte. Pero por si esto no fuese suficiente, luego de la resolución del caso "Castillo Petruzzi" debieran ser vistos por ese Alto Tribunal Internacional procesos como los seguidos contra el Estado Peruano por el empresario Baruch Ivcher o los ex integrantes del Tribunal Constitucional, procesos en donde la casi segura condena a las acciones asumidas por el gobierno fujimorista y su mayoría parlamentaria iban a tener unas repercusiones políticas francamente inconvenientes para un grupo político que está pretendiendo continuar manteniendo el control del poder luego de las elecciones presidenciales y parlamentarias de Abril del año dos mil.

39 Nos estamos aquí refiriendo al pronunciamiento emitido por la Sala Plena del Consejo Supremo de Justicia Militar el 11 de Junio de 1999 y publicado en el Diario Oficial «El Peruano» del día 12 de ese mismo mes y año. En dicho pronunciamiento, argumentándose una discutida y discutible superioridad de lo prescrito en el Texto constitucional peruano de 1993 frente a lo dispuesto en el Pacto de San José de Costa Rica, alega que los magistrados de la Corte Interamericana de Derechos Humanos han asumido competencias que no le corresponden y concluye que el fallo emitido por este Alto Tribunal Internacional es inejecutable. En nuestra modesta opinión, aun admitiendo un supuesto rango infraconstitucional de los tratados dentro del ordenamiento jurídico peruano, lo resuelto por este Consejo carece de todo sentido, pues la actuación y el pronunciamiento de la Corte Interamericana no se da como consecuencia de que exista un Pacto de San José sino fundamentalmente debido a que es el mismo artículo $205^{\circ}$ de la Constitución Peruana de 1993 la norma por la cual se habilita a toda persona no conforme con lo resuelto por las instancias jurisdiccionales nacionales puede llevar su caso a un escenario tuitivo de carácter internacional. 
rechazar el fallo emitido en su contra, sino que además mediante Resolución Legislativa número decidirá apartar al Perú de la competencia contenciosa de la Corte Interamericana de Derechos Humanos, decisión a la cual además se asume como de aplicación inmediata.

Independientemente de algún aspecto del pronunciamiento de la Corte con el cual podríamos estar en desacuerdo ${ }^{40}$, lo cierto es que en líneas generales el fallo de ese alto tribunal se nos presenta como ajustado a lo prescrito en la Convención americana y a lo resuelto anteriormente por esta importante instancia jurisdiccional en situaciones similares. Por otro lado, los argumentos esgrimidos por el actual gobierno peruano para sustentar su decisión (la constatación de una serie de eventuales perjuicios a la estrategia antisubversiva puesta en práctica por ellos y la consideración de la aceptación de la competencia contenciosa de la Corte como un mero acto unilateral claramente escindible de la suscripción del Pacto de San José, tratado cuya vigencia en el Perú asumen no haber menoscabado ${ }^{41}$ nos parecen débiles e insuficientes

40 Por ejemplo, nos parece equivocada la posición asumida por el Alto Tribunal cuando señala que el hecho de juzgar en tribunales peruanos a cuatro ciudadanos chilenos por supuesta traición a la patria no constituye una violación del derecho a la nacionalidad previsto en el artículo 20 del Pacto de San José de Costa Rica. Por otro lado, se nos presenta como sumamente tibio y poco claro el pronunciamiento efectuado por la Corte frente al siempre delicado tema de los llamados «jueces sin rostro", materia en la cual resultaba indispensable expresar una opinión bastante más concluyente que la recogida en el párrafo 133 de la sentencia que venimos comentando, párrafo en el cual se dice lo siguiente:

«[...] 133. Además, la circunstancia de que los jueces intervinientes en procesos por delitos de traición a la patria sean "sin rostro", determina la imposibilidad para el procesado de conocer la identidad del juzgador $y$, por ende, valorar su competencia. Esta situación se agrava por el hecho de que la ley prohibe la recusación de dichos jueces».

$41 \mathrm{La}$ posición asumida por el actual gobierno peruano, además de buscar desinformar a la opinión pública de nuestro país con lecturas del fallo de la Corte Interamericana que bajo ningún concepto responden a la realidad, apunta a considerar a la suscripción del Protocolo por el cual el Estado Peruano se somete a la competencia de la Corte como un acto unilateral completamente escindible del compromiso asumido por el Perú al suscribir la Convención Americana de Derechos Humanos. Con ello busca justificar su desentendimiento de la competencia contenciosa del Alto Tribunal al cual venimos haciendo referencia sin necesidad de denunciar el Pacto de San José y, consecuencia lógica de ello, sin tener que esperar un año para recién poder sustraerse de la obligatoriedad de los pronunciamientos efectuados por esa importante instancia jurisdiccional, tal como dispone en estos casos el mismo texto de la Convención Americana. 
como justificantes de la postura asumida por el fujimorismo y sus seguidores sientan un pésimo y muy peligroso precedente: el de ser (por lo menos en el escenario latinoamericano) el primer país que tan radical y, abiertamente se niega a cumplir siquiera en términos formales con la sentencia de un Tribunal internacional cuya competencia había inicialmente admitido de forma completamente libre y soberana ${ }^{42}$.

\footnotetext{
Ahora bien, aun asumiendo la muy discutible postura de que nos encontremos frente a un acto unilateral, ni siquiera ello parece resultar argumento suficiente para justificar la posición defendida por el actual gobierno peruano, la cual abiertamente intentaría así desconocer principios y criterios de interpretación hoy plenamente aceptados por todos los países del mundo, principios como el pro-homine o el de intangibilidad de los tratados. La debilidad de la argumentación esgrimida por el fujimorismo y sus aliados es tal entonces que en nuestra modesta opinión no resiste ningún análisis medianamente riguroso. Sin embargo, ello no nos libera del reto planteado por un caso como éste, el cual es a saber el de como asegurar el pleno cumplimiento de lo resuelto por una instancia de la llamada Jurisdicción Internacional cuando un país sometido voluntariamente a su competencia intenta luego unilateralmente sustraerse de ella. Asimismo, cabe preguntarse sinceramente en este contexto cual es el verdadero valor y respeto reconocido a la Convención Americana de Derechos Humanos si es que no se admite la competencia de aquella instancia jurisdiccional cuya finalidad es precisamente la de sancionar a quien intenta vulnerar las prescripciones recogidas dentro de tan importante tratado internacional.

42 Justo es señalar como en 1998 ya se había producido alguna diferencia entre las diversas instancias destinadas a la tutela de los diferentes derechos y uno de los países hasta entonces signatarios de la Convención Americana de Derechos Humanos. Nos estamos aquí entonces refiriendo al caso de Trinidad y Tobago, al cual sucintamente pasaremos a referirnos.

El entrampamiento entre Trinidad y Tobago y todo el aparto tuitivo de derechos a nivel Interamericano se produce ante la intención de esa nación caribeña de ejecutar a una serie de personas que consideraban de suma peligrosidad para la propia estabilidad de dicho país. Sin embargo, dicha decisión no podía llevarse a la práctica en mérito a los compromisos asumidos por Trinidad y Tobago al suscribir la Convención americana de Derechos Humanos. Es entonces que el Estado antes mencionado, sin jugar a desconocer ningún pronunciamiento correctamente emitido o intentar cuestionar la legitimidad e idoneidad de aquellos que únicamente vienen limitándose a cumplir con sus obligaciones, opta por denunciar el Pacto de San José de Costa Rica, en Mayo de 1998, decisión que recién se ha hecho efectiva un año después, tal como prescriben las normas existentes al respecto. En síntesis, aun cuando nos encontremos ante una situación que tampoco merece nuestro respaldo, resulta imposible el intentar asimilar lo ocurrido en el caso de Trinidad y Tobago a las especiales características de lo sucedido en el Perú, salvo mejor parecer.
} 
El problema es entonces en este caso específico, al igual que en otros similares que esperamos no vayan a volver a presentarse, el de cómo asegurar la ejecución de las sentencias emitidas por una instancia de la denominada Jurisdicción Internacional si es que algún Estado se resiste a aceptar dicho mandato, máxime si estos pronunciamientos, a diferencia con lo que ocurre por ejemplo con lo que pueda ocurrir en el escenario comunitario europeo ${ }^{43}$, no cuentan siquiera con algún mecanismo de presión económica para así forzar su cumplimiento.

Ciñéndonos a lo que podría ser una interpretación más bien coherente con lo dispuesto por la Convención americana de Derechos Humanos y los diferentes tratados destinados a regular la estructura y funcionamiento de la Organización de Estados Americanos, lo único que cabría hacer frente a un caso como el generado por el actual gobierno peruano es, además de continuar con los procesos oportunamente iniciados ante el Sistema Interamericano de Derechos, el esperar que tanto el Secretario General como el pleno de la Asamblea de la OEA se pronuncien condenando enérgicamente a aquellas autoridades estatales cuya actitud se encuentra muy lejos de apuntalar los múltiples esfuerzos hoy y anteriormente efectuados para fortalecer la plena vigencia de los Derechos Fundamentales tanto dentro de los ordenamientos jurídicos de los diversos países como en el plano internacional ${ }^{44}$.

43 Como es de público conocimiento, en el modelo comunitario europeo las labores destinadas a asegurar el pleno cumplimiento de la normatividad emitida por la UE y de lo resuelto por el Tribunal de Justicia de las Comunidades Europeas tienen como mecanismos de presión a su alcance el de la prohibición del acceso a los fondos comunitarios (fondos de invalorable relevancia para el funcionamiento de la economía de la mayor parte de los estados miembros) a los Estados renuentes a cumplir con este tipo de obligaciones que en su momento voluntariamente admitieron. Ahora bien, la aplicación de mecanismos similares en el ámbito de la protección Internacional de Derechos se nos presenta como muy compleja no solamente en mérito a la diferente naturaleza de los dos modelos comparados, sino también a la ausencia de recursos económicos a cargo de instancias como la Corte Interamericana de Derechos Humanos, recursos con los cuales dichas instancias si podrían contar con un instrumento destinado a asegurar la mayor exigibilidad de sus fallos.

44 En esta línea de pensamiento parece ubicarse la reciente decisión de la Corte Interamericana de Derechos Humanos mediante la cual dicha instancia declara inadmisible la decisión peruana de rechazar la competencia contenciosa de ese Alto Tribunal. Ello implicará seguramente que los procesos continúen con un Estado peruano 
La continuación de los procesos pendientes de resolución seguidos contra el Estado peruano y la realización de drásticos pronunciamientos condenatorios a la actitud asumida por sus actuales gobernantes devienen pues en este contexto en acontecimientos de indispensable realización para así preservar la credibilidad de todo el sistema interamericano de Derechos Humanos. Así por lo menos, quedará claro que en un mundo globalizado como el nuestro la defensa de los derechos es una obligación de ineludible cumplimiento para todo gobernante, so pena de convertirse y convertir al Estado que dirigen en un paria internacional. Sin duda esta condena de tipo más bien moral todavía parece insuficiente para asegurarnos el cumplimiento de los mismos, pero si lo comparamos con la situación existente hace algunos años al respecto, nos encontramos frente a un importante avance cuya relevancia no podemos soslayar, aun cuando los riesgos y asignaturas pendientes sobre el particular todavía son muy grandes, y es más, nos obligan a tomar grandes precauciones para no perder todo lo históricamente ganado con tanto esfuerzo.

\section{Algunas notas sobre el particular a modo de conclusión}

En un mundo como en el que nos toca vivir, mundo en el cual la plena vigencia de los Derechos Fundamentales es vista como un verdadero elemento promotor de una mejor convivencia y desarrollo de todas las personas, resulta entusiasmante comprobar como el llamado proceso de internacionalización de los Derechos Humanos ha permitido la configuración de un escenario tuitivo que no solamente repara las injusticias y desmanes cometidos en diversos países, sino que además está cumpliendo el importantísimo rol de reforzar o completar los mecanismos destinados a la tutela de esos derechos a nivel nacional, espacios en los cuales muchas veces los instrumentos previstos para desempeñar dichas labores no estaban todo lo bien diseñados que se quisiera o simplemente, a diferencia de lo que sucede en otros Estados, no existían o no funcionaban debidamente.

en situación de rebeldía. Queda entonces por verse si la intención de la Corte de no abdicar en sus funciones será explícitamente apoyada por los organismo del más alto nivel dentro de la Organización de Estados Americanos. 
Ahora bien, ello no obsta para reconocer que dicho proceso es aún incompleto, y además, sujeto a una serie de marchas y contramarchas. Sin embargo, haciendo un balance de lo expuesto, el desarrollo de los mecanismos propios de la llamada Jurisdicción Internacional es positivo, obligando a los estudiosos del Derecho Constitucional como al resto de los ciudadanos a comenzar a mirar la labor de estas instituciones y preceptos sin el escepticismo que suele surgirnos cuando hacemos frente a algo a lo cual asumimos como poco eficaz, o, porque no decirlo, despojados de la desconfianza que nos provoca aquello que aparentemente sin mayor sustento parece atentar contra lo plasmado en nuestros ordenamientos jurídicos nacionales y poner en entredicho la soberanía de nuestros diversos Estados. La reacción aconsejable hoy pareciera ser pues exactamente la contraria, y la tarea a asumir, a la luz de los valiosísimos resultados que con ello podemos alcanzar, debiera más bien estar encaminada a apuntalar una mayor difusión y colaborar con un mejor desarrollo de las condiciones que permitan el pleno cumplimiento de los pronunciamientos emitidos por estas diversas instancias de jurisdicción internacional. En síntesis, el aprovechar las evidentes e innegables ventajas que estos nuevos espacios e instrumentos tuitivos nos proporcionan se nos presenta entonces como una tarea de indiscutible necesidad y conveniencia en la cual todos deberíamos colaborar, salvo mejor parecer. 